\title{
Seismological Survey of the Coal Fields Based on the Applying of the Low-Power Sources of Oscillation
}

\author{
Oleg Tailakov ${ }^{1,2, *}$, Sergey Sokolov ${ }^{1}$, Maxim Makeev ${ }^{1}$, and Alexei Kormin ${ }^{1}$ \\ ${ }^{1}$ Institute of Coal, Federal Research Center of Coal and Coal Chemistry SB RAS, 650065 Kemerovo, 10 \\ Leningradsky ave., Russian Federation \\ ${ }^{2}$ T.F. Gorbachev Kuzbass State Technical University, Underground Mining Department, 650000 \\ Kemerovo, 28 Vesennya st., Russian Federation
}

\begin{abstract}
. the application of seismoacoustic profiling by the method of a common depth point (CDP) to clarify the geological conditions of the coal fields, to determine the location and extent of the existing faults is considered. The results of measurements made in the Kuznetsk Coal Basin (Kuzbass) on the basis of the use of longitudinal and shear elastic waves generated by a source of low power oscillations are presented. The field measurements have been made on the two surface geophysical profiles with the total length of $1048 \mathrm{~m}$. The proposed approach allowed reaching the depth of the transverse waves distribution at the level of 300 meters and can be effectively used as complementary to other studies in determining the filtration properties and permeability of coal seams with the aim of developing measures for their degassing and subsequent utilization of coalmine methane.
\end{abstract}

\section{Introduction}

Applying of the seismological survey is an effective way to produce geological mapping, analyze the state and properties of the rocks in coal mining [1]. Despite of fact that there are some factors that complicate the interpretation of the seismic data obtained in the study of coal deposits, e.g. fairly low average thickness of coal seams in comparison with their depth, a small amplitude of the faults and the presence of the multiple interference of different nature and etc., the methods and equipment of the seismic research of coal seams is rapidly developing.

The application of these methods makes it possible to determine geological faults, areas of weakening of the above and below coal seams laying strata and possible directions of migration of coalmine methane, as, for example, shown schematically in Fig. 1. This studies supplement information that can be obtained by applying injection fall-off tests [2] or determining the gas content of coal seams in desorption tests [3], to improve the efficiency of their degassing and following up utilization of coalmine methane [4-15].

\footnotetext{
* Corresponding author: tailakov@uglemetan.ru
} 


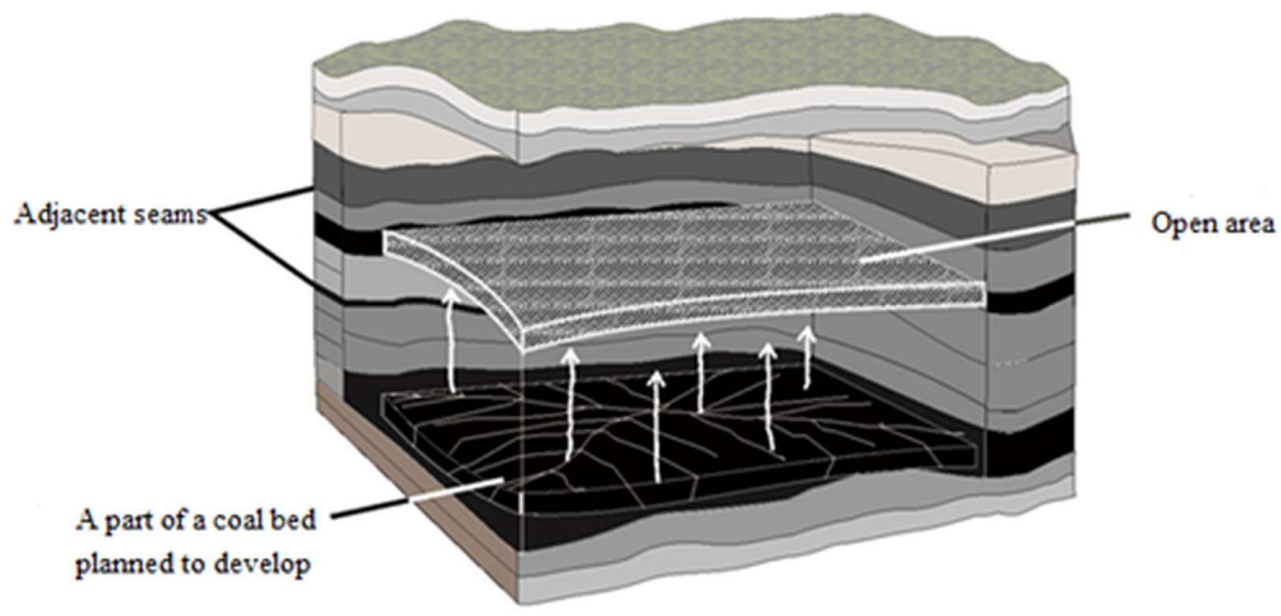

Fig. 1. Change of coalmine methane content as a result of working-off of above laying coal beds.

\section{Field measurement}

To determine the possibility of the applying of the surface seismic exploration techniques based on the elastic waves of low power usage for the purposes of the defining geological conditions of the coal deposits the seismic studies are produced on mining allotment of one of the mines of Leninskiy geological and economic district in Kuznetsky Coal Basin (Kuzbass). The use of lowpower sources of oscillations was an important feature of this work, which has provided efficiency and has significantly reduced the cost of the study. Conditions of coal seams' bedding of investigated site were characterized by rhythmic alternation of sandy-clay soils: siltstone, mudstone and fine-grained sandstones, which are significantly different because of its seismic and density properties of coal.

The field measurements have been made on the two surface geophysical profiles with the total length of $1048 \mathrm{~m}$, characterized by rather difficult hilly nature of the terrain (Fig. 2). For the seismic research a scheme based on the assessment of the reflected waves by the common depth point method (CDPM) is chosen. The research occurred by the means of stimulation and recording of longitudinal and transverse waves (P-waves and $\mathrm{S}$-waves).

For the work on longitudinal waves there was chosen a scheme with flank system disposal, the maximum length of the hodograph $188 \mathrm{~m}$, with $18 \mathrm{~m}$ step between receivers, $4 \mathrm{~m}$ distance between points of vibration excitation in the profile 1 , and $8 \mathrm{~m}$ - in profile 2 . There were 48 active channels used with the multiplicity 24 to a common depth. A pulsed vibration source was used for the excitation of elastic waves. Fluctuations were initiated by a shot with 12 caliber cartridges with a blank charge of smokeless powder in a well with the depth of $50 \mathrm{~cm}$ with water capping.

Central, asymmetrical arrangement of the system with length of hodographs 140 and $48 \mathrm{~m}$ on the left and right branches, respectively, step between receivers of $4 \mathrm{~m}$ between picket's vibration source $4 \mathrm{~m}$ and multiplicity by CDP - 24 was used for the work on the transverse waves. As an oscillating source was a mechanical device excitation of elastic vibrations like "harrow". 


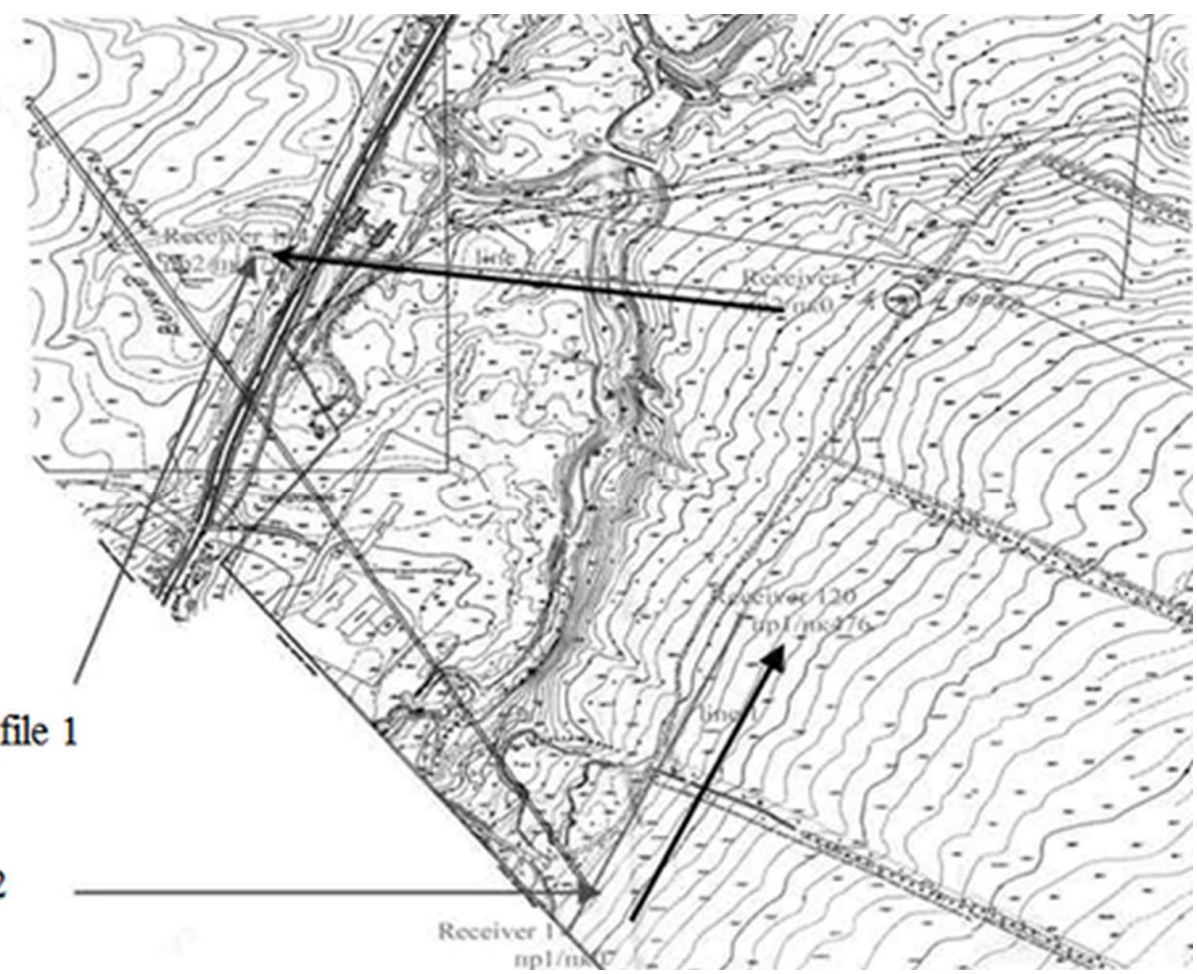

Fig. 2. Scheme of the emplacement of geophysical profiles.

As a result of the application of seismic research there was received comparative material CDP, sufficient for resolving researching tasks, with the use of longitudinal and transverse waves, which allowed to make an analysis both reflected and refracted waves. Defining the parameters of occurrence of roof coal measures corresponding to the refractive surface in the upper part of the section was carried out on the results of the data by the method of refracted waves. The position of refractor and boundary velocities was determined with the interpretation of data by the method of refracted waves. Analysis of the boundary velocities of longitudinal and transverse waves on different hodographs by scanning at various bases allowed us to determine the velocity of seismic waves for:

- covering thickness of unconsolidated sediments $\mathrm{Vp}=400-500 \mathrm{~m} / \mathrm{s}, \mathrm{Vs}=200-280 \mathrm{~m} / \mathrm{s}$;

- roofing aquifers near the surface of the coal-bearing strata of $\mathrm{Vp}=1500-1700 \mathrm{~m} / \mathrm{s}$; and

- coal-rock Vp=2500-2700 m/s, Vs $=1000-1200 \mathrm{~m} / \mathrm{s}$.

CDP data processing was applied in order to convert the collected data into the seismic section. To reduce noise in the process of separation of the desired signal the seismic records were filtered. The analysis of the frequency content of seismograms has shown that the spectrum of the desired signal is in the range $10-60 \mathrm{~Hz}$. Thanks to the results of spectral analysis of seismic records there were identified band pass filtering options: 6-12-40-80 Hz. To bring the seismic trace to a stationary form and to compress dynamic range the AAC with the window rate of 100 ms was used. Sufficiently high quality of the seismic data determined a small number of culled tracks before the CDP summation procedure. Receiving of the prior time section preceded the input of kinematic corrections and the procedure of muting. The result of processing seismic data has shown that for the conditions of steep seams of Kuzbass it is useful to do time (or depth) migration up to summation of CDP.

Seismograms recorded by using a source of transverse vibrations were characterized by good quality of hodographs and a minimum of hindrances. This was due to the fact that the work was 
carried out in winter in seasonal freezing soil. Depth distribution of the transverse waves reached 300 meters. Final depth seismic section for transverse waves is shown in Fig. 3.

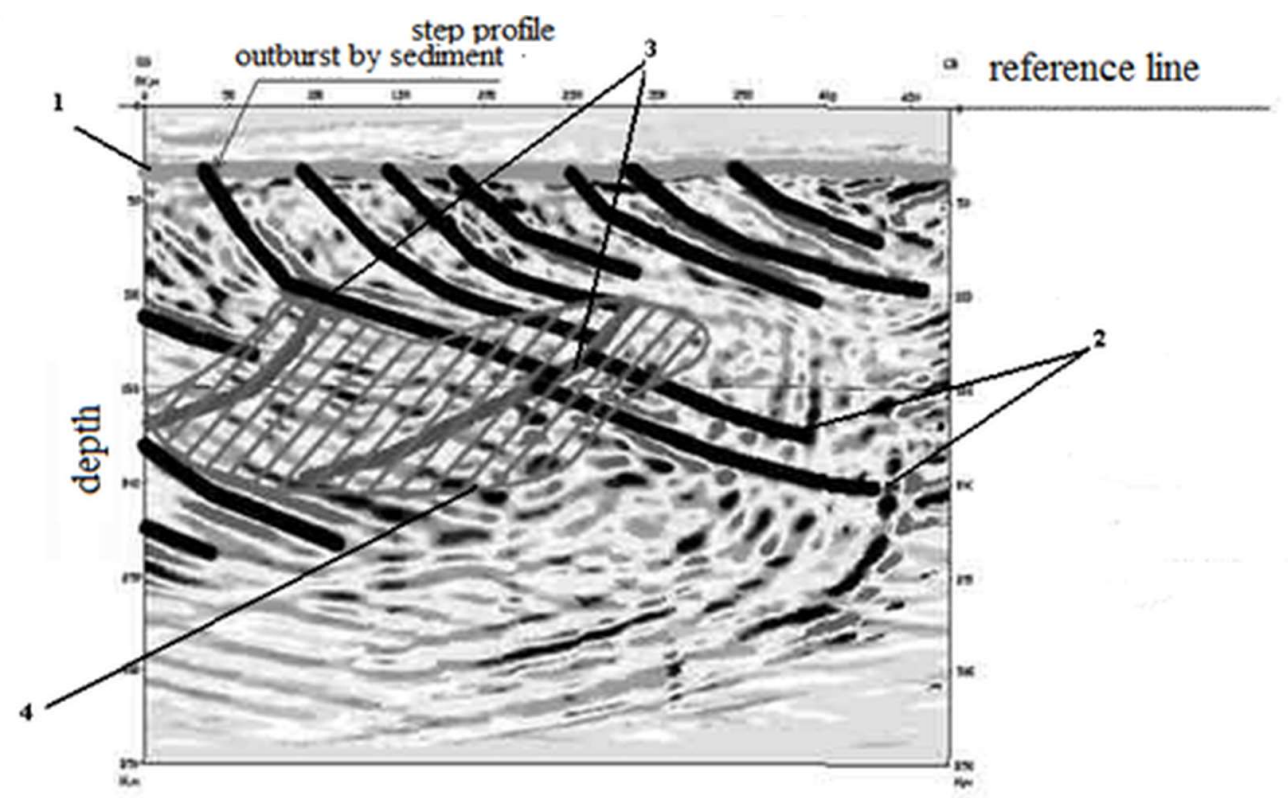

Fig. 3. Final depth seismic section obtained by the transverse waves: 1 - top of the coal-bearing strata; $2-$ coal beds; 3 - disjunctive violations; 4 - area of disjunctive dislocations.

\section{Conclusions}

The analyses of the results of the produced seismological survey have shown that in the seismic time sections, built on the level of the surface, the most dynamic expression was subhorizontal reflection that was traced to the time of $250-270 \mathrm{~ms}$ associated with the roof coal measures at a depth of about $40 \mathrm{~m}$. In the time interval of 200-250 ms there were defined subhorizontal reflections formed in the thickness of the covering of loose sediments. Under the sub-horizontal reflection, it was recorded a range of intensive allowed oblique axes in phase, identified as reflections from coal seams. As a result of the interpretation of the deep cuts the following main elements of the structure were marked:

- roof-coal-bearing strata at a depth of 40-45 m;

- a range of coal seams that go under the sole of the overburden; and

- a region at a depth of 150-230 m, where there are violations in tracking coal seams associated with faulting.

Analysis of data from the longitudinal and transverse waves confirmed the validity of the allegations about the dependence of deviations of amplitude and frequency characteristics of reflected waves from the size of the area is likely to accumulate methane.

\section{References}

1. O. Yilmaz, S. Doherty, Seismic data analysis: processing, inversion, and interpretation of seismic data (Society of the Exploration Geophysicist, Lindon, 2001)

2. O. Tailakov, E. Utkaev, D. Zastrelov, S. Sokolov, Applied Mechanics and Materials, 770, 349 (2015) 
3. L. Nazarov, L. Nazarova, D. Vandamme, J.-M. Pereira, I. Tahiri, Sixth Biot Conference on Poromechanics (American Society of Civil Engineers, New York, 2017)

4. A. Baklanov, S. Valiulin, S. Dubtsov, V. Zamashchikov, A. Korzhavin, A. Onischuk, P. Purtov, V. Klishin, D. Paleev, A. Kontorovich, Doklady Physical Chemistry 461, 57 (2015)

5. O. Tailakov, D. Zastrelov, V. Tailakov, M. Makeev, P. Soot, E3S Web of Conferences, 21, 02014 (2017)

6. E. Kozyreva, E. Nepeina, E. Tsuran, M. Plaksin, Coke and Chemistry, 60, 404 (2017)

7. W. Diamond, S. Schatzel, International Journal of Coal Geology, 35, 311 (1998)

8. J.-Z. Han, S.-X. Sand, Z.-Z. Cheng, H.-Z. Huang, Mining Science and Technology, 19, 0025 (2009)

9. K. Warmuzinski, Process Safety and Environment Protection, 86, 315 (2008)

10. R. Potokina, N. Zhuravleva, Z. Ismagilov, Chemistry for Sustainable Development, 21, 485 (2013)

11. O. Tailakov, V. Tatsienko, A. Kormin, A. Smyslov, Journal of Mining Science, 51, 1203 (2015)

12. A. Dement'ev, A. Moiseeva, Y. Krainov, D. Paleev, Journal of Engineering Physics and Thermophysics, 89, 1514 (2016)

13. D. Williams, A. Saghafi, D. Drummond, D. Roberts, Symposium on Coalbed Methane Research and Development in Australia (James Cook University of North Queensland, Townsville, 1992).

14. V. Klishin, D. Kokoulin, B. Kubanychbek, A. Gurtenko, Journal of Mining Science, 46, 411 (2010)

15. A. Zhou, K Wang, L. Fan, T. Kiryaeva, International Journal of Mining Science and Technology, 27, 675 (2017) 